\title{
A Critical Assessment of Macro-Economic, Management and Policy Reforms in Africa
}

\author{
Wilfred Awung Ndongko ${ }^{1}$ and Ismaila Amadu ${ }^{2 *}$ \\ 1: Cameroon Academy of Sciences, Cameroon \\ 2: National Committee for the Development of Technologies, Ministry of Scientific of Research and Innovation, \\ Cameroon \\ *Corresponding author's email: ismailaamadu@yahoo.co.uk \\ P.O.BOX 1457 Yaounde, Cameroon
}

\begin{abstract}
The paper assesses the macro-economic, management, and policy reforms implemented in Africa with the assistance of the Bretton Woods institutions. There is no doubt that they have, to some extent, improved the socioeconomic development of African countries. However, they did not take into account the social dimension of their economies (health, education, poverty, employment, etc.). Thus, they were regarded not to have a human face. Therefore, redressing and adjusting African economies with the help of the Bretton Woods institutions are inadequate to propel the continent to higher and sustainable economic growth rates. Hence, African countries should elaborate and implement themselves policies, reforms, and programs adapted to their economies and development needs.
\end{abstract}

Keywords: Macro-Economic, Management, Policy Reforms, CEMAC, Africa

DOI: $10.7176 / \mathrm{EJBM} / 12-9-10$

Publication date:March $31^{\text {st }} 2020$

\section{Introduction}

\subsection{Socio-economic context}

The first twenty years of independence of African countries was consecrated to the consolidation of political power and national sovereignty. However, the continuous existence of multiple socio-economic and political colonial enclaves frustrated the efforts of African countries to get national sovereignty. The urgent impetus had been taken at the level of the then Organization of African Unity (OAU) to accord priority to the economic, social, and cultural dimensions of political independence through the establishment of LPA, FAL, etc.

\subsection{Pre - 1980 Socio-Economic Situation}

Political fragility in Africa has been compounded by the economic, social, and cultural weakness of many countries on the continent. Development policies and programs in Africa have been based on the dominant role of international aid agencies, financial institutions, and private foreign investment. World Bank and Pearson Reports revealed that of 36 Less Developed Countries-LDCs (1979) in the World, 23 of them were in Africa. African countries were also negatively affected by the counterproductive national development policies and strategies (Import Substitution and Nationalization of Private Enterprises, etc.). Highest death rates, low life expectancy rates, the decline in food self-sufficiency, weak production base, and inefficient utilization of human resources, resulting in enormous Brain Drain from the African countries to developed and industrialized nations, were experienced by many African countries (Paul and Jan 1999). By 1997, African countries accounted for only $2.7 \%$ of the World's Gross National Product (GNP) and had the lowest average annual per capita income in the World (World Bank, 2014).

\subsection{The Genesis of the Socio-Economic and Financial Crisis}

Errors that were made in economic policy formulation and management during the 1960s and 1970s, particularly in the neglect of the agricultural sector, became apparent, and this resulted in the recession of the 1980s (Paul and Jan 1999). Substantial deterioration of socio-economic indicators (disintegration of productive and infrastructural facilities, rapid worsening of the social amenities, repeated droughts, and accelerated environmental degradation). The perennial socio-economic crisis affected the foundations of long-term stable economic growth and development prospects of the African continent (Paul and Jan 1999). Investment ratio declined from 24.5\% of GDP in 1970s to 15.5\% of GDP by 1989 (Paul and Jan 1999). Reduction of trade surplus of 81.8 billion and 29 billion in 1960 and 1970s respectively, to a deficit of US\$ 256.9 billion in 1989 (Robert and Jong 1993). External Debt situation and obligations continued to worsen as the stock of Debt rose from \$138 billion in 1982 to \$149.9 in 1988 and over $\$ 300$ billion by 1995 . Inflationary rates generally remained high; about $30 \%$ on the average has 
been recorded in many African countries. Average consumer prices, which ranged between $10.2 \%$ in 1985 and $12.9 \%$ in 1987 , escalated to $21 \%$ in 1988 and 1989 and thus reducing the purchasing power of the average African during the period under review (Robert and Jong, 1993).

\subsection{Influence of Internal and External Factors}

\section{(i) Internal Factors}

- Lopsided socio-economic development between urban and rural areas;

- Extreme socio-economic disparities between urban and rural areas;

- Economic and financial inequalities between people and regions;

- The political context of the African continental economy reflected by the very nature of the democratic processes and practices;

- Institutional setup dominated by bureaucracy as well as the limited internationalization or appropriation and adoption of norms, and values imported from foreign institutions;

- Gross mismanagement of the African economy, policy discontinuity, and uncertainty;

- Weaknesses of the production base of the African economies to external influences and its openness perpetuated and reinforced the continent's foreign dependence;

- The dominance of the external sector rendered national economies highly vulnerable to external shocks.

(ii) External Factors or Shocks

- Poor weather and droughts drastically affected the agricultural sector of the African economies;

- Declining world commodity price resulted in perennial trade and current account deficits of the balance of payments;

- Mounting External Debt Burden and Servicing Obligations;

- Hostile international economic, financial and political environment;

- Drastic reductions in the flow of foreign direct private investment;

- Diminishing bilateral and multilateral development and technical assistance

- Drastic fall in the prices of agricultural and primary products.

\section{The Nature of the Macro-Economic and Policy Reforms 2.1. International Monetary Fund (IMF) Stabilization Policies}

Nominalization to reduce or eliminate short-term disequilibria in African economies (budget deficits, the balance of payment deficits, and inflation). The three categories of IMF supported policy packages are:

(i) Demand Retrain Policies: Designed to reduce demand in the economy in order to curtail expenditures on imports and release resources for export production. Relevant policy instrument includes a reduction in government expenditures, reductions in the budget deficit, control over the money supply and credit creation, and wage reductions.

(ii) Switching Policies: Formulated to shift from none-tradeable to tradeable by altering the incentive system. Devaluation and Exchange Rate unification are the main policy instruments, accompanied by changes in domestic prices.

(iii) Long-term Supply Policies: They intended to increase the long-term inefficiency of the national economy. The policies include trade liberalization, domestic price reforms, and financial reforms.

(iv) In the CEMAC in general and in Cameroon in particular, through the medium of SAPs, the IMF established a general framework, covering areas and policies to be implemented, which principally focused on the stabilization of the public finances and stimulation of the economy.

(v) To implement them, three approaches were put in place: action on supply, on demand, and simultaneous actions on both.

(vi) Due to the slow response of production mechanisms and the fact that the government initially opted for a rapid adjustment priority has been given to action on demand, although the programs chosen will eventually incorporate the necessary measures regulating domestic supply. 


\section{II.2. World Bank Structural Adjustment Policies}

Emphasis is placed on monetary and fiscal policies, maintaining appropriate real exchange rates and interest rates, as well as liberal approaches to an external account balance of payments, capital and current accounts, SAPs, and Policy Instruments have five main categories:

- Mobilization of resources through fiscal and credit policies and improved financial performance of public enterprises;

- Improvement in the utilization of resources in the public sector enterprises;

- Trade policy reforms include liberalization removal or reduction of import quotas, lowering of tariffs, etc.;

- Institutional reforms to improve capacity in the public sector;

- Social policy reforms (SDA relatively new);

- In CEMAC countries, privatization and deregulation policies have been initiated to improve the performance of enterprises.

It is worth noting that the SAPs implemented in most African countries, including the CEMAC zone, were quasi the same but with different severity and speed. Moreover, the responses of the various economies to the SAPs and the magnitude of their consequences on the various African countries differed to some extent. To this effect, the scale of the negative impact of the SAPs on employment, poverty, health, and social structure could not be the same across the African continent.

\section{Critique of Macro-Economic Policy Reforms}

The SAP's were introduced as a result of the failure of domestic macro-economic and financial policies and not as a deliberate attempt to redress the economic situation of African countries. No explicit mention of the need to restructure the existing production and consumption patterns in Africa to achieve rapid economic recovery collected self-reliant development and sustainable growth and improved standards of living. IMF and World Bank have been the dominant source of influence over African economic policy formulation, management, monitoring, and evaluation.

The Impact of IMF and World Bank Policies in Africa

- Caused untold hardship on the African population at large led to considerable losses in postindependence gains in socio-economic developments and the welfare erosion of populist economic programs initiated at dawn of independence;

- Compromised the position of the African nations as a symbol of national and political sovereignty;

- Revealed the weak and dependent character of the African countries vis-a-vis foreign powers and financial institutions;

- The continuous presence of expatriate economic experts in the African countries led to glaring marginalization of local expertise and decision-makers;

- The sudden shift from economic conditionalities to political conditionalities implied the linking of SAPs to the process of democratization;

- Human and social costs of SAPs were alarming as revealed by ILO (1997) on the impact of SAPs on the vulnerable groups-women, children and the poor at large;

- The preceding negative impact forced the African countries to initiate appropriate socio-economic and financial measures and development strategies within the context and guidelines of the African Alternative Framework for Structural Adjustment Programmes (AAF-SAP), which placed the human dimension at the center of the Macro-Economic Policy Reforms.

\section{Recent Economic and Financial Reforms in the Economic and Monetary Community of Central African States (CEMAC)}

- To adequately respond to the falling oil and commodities prices and diminishing exchange reserves; and reduce the negative impact on the CEMAC zone, the member states initiated a series of policy measures that were to be negotiated and implemented with the assistance of the IMF and the World Bank (CEMAC Commission, 2018); 
- The policy measures included budgetary reforms, monetary and financial reforms, structural reforms, and regional integration. The implementation of the reforms was done with the assistance of the IMF, meanwhile those of the Structural Reforms and Regional Economic Integration with that of the World Bank.

\subsection{Budgetary Reforms}

They aimed at strengthening the fiscal policy to improve the revenue of the member states through:

- The increase in the effective pressure rate of indirect taxes (VAT and Excises duties) and reducing direct taxation, particularly those on corporate profits, so as improve their competitiveness;

- The improvement of the quality of public expenditure by implementing targeted fiscal policies. To avoid compromising benefits of economic growth, public expenditure reduction was not limited solely to investment;

- The harmonization of procedures and improvement of the coordination of budgetary policies, which are essential for the consistency of the Monetary Union and financial integration.

\subsection{Monetary and Financial Reforms}

- The replenishment of foreign reserves of member countries by enforcing exchange regulations, precautionary measures as provided for in the statutes of BEAC and the repatriation of assets by States.

- Strengthening the effectiveness of monetary policy by respecting the independence of the Central Bank. The new Statutes of the Bank of Central African States (BEAC), which aim at increasing its autonomy and financial transparency, must, therefore, be rapidly implemented;

- Strengthening stability and financial inclusion as well as fighting against money laundering and blackmarket activities undertaking;

- Revitalization of financial markets should be undertaken by increasing the depth and potential of the Stock Market.

- The reform of the Development Bank of Central African States (BDEAC) so that it adequately plays its role in supporting the private sector and financing.

\subsection{Structural Reforms}

- Strengthen the diversification of the economy and private sector development;

- To improve the business climate and enhance private investment;

- Increase and diversify the sources of financing development projects.

\subsection{Regional Economic Integration}

- Accelerate the putting in place a single market by eliminating tariffs and non-tariffs barriers as well a common customs union;

- Strengthening of the national and community statistical systems;

- Accelerating the implementation of the second operational plan of road infrastructure and telecommunication projects for the period 2017-2021;

- The adoption of the Regional Economic Programme of CEMAC during the Conference of the Heads of States of the member countries in 2010, in Bangui, Central African Republic (CAR). This is to reinforce and accelerate Regional and Economic Cooperation among the CEMAC member countries (African Development Bank, 2019);

- The various CEMAC member states decided, on February 17, 2017, in Djibloho, Equatorial Guinea, that every citizen of the economic zone in possession of a valid biometric passport, could travel to each member country without a visa to facilitate the movement of people and ease doing business in the Sub Region (CEMAC Commission, 2018); 
- Also, Cameroon ratified, in 2014, the Economic Partnership Agreement with the European Union (EU), which allows the later to export some of its products to Cameroon without paying customs duties.

Although most of the policy reforms undertaken in recent years in CEMAC are yet to be completely implemented and evaluated, it could be observed that:

- The implementation of some of these reforms, particularly those aimed at improving the quality of public expenditure enabled the CEMAC zone to maintain a positive economic growth rate (African Development Bank, 2019);

- $\quad$ The reforms equally played a role in improving the exchange reserves of the various member states and excluded the possibility of the devaluation of the Francs CFA;

- However, measures taken to improve integration, particularly the free movement of people and goods and services within the economic zone seem not to have been entirely implemented as countries like Gabon, and Equatorial Guinea are still restricting the entry of people as well as goods and services into their territories (African Development Bank, 2019). All this is to some extent, to prevent the sales of European products that are entering the CEMAC zone without paying customs duties through Cameroon, which signed a trade agreement with the EU, letting in some products from the later to its territory custom free.

- There is no doubt that the Free Trade Agreement is negatively affecting the performance and competitiveness of rival enterprises in Cameroon and the Sub Region, implying that the terms of the free trade agreement between Cameroon and the EU did not take into account the economic realities of Cameroon and those of the CEMAC zone (Cameroon Chamber of Commerce, Industry, Mines, and Crafts, 2018).

\section{Considerate for the Design and Implementation of Future Macro-Economic Policy Reforms}

- Incorporate, through contingency arrangements, the possibility of the impact of enormous terms of trade stocks on African countries resulting from the volatility and decline in real prices of primary commodities;

- Recognize the need for the "Local Ownership" of the SAPs and stabilization programs since the best SAP package cannot succeed in a country if the government responsible for its implementation does not see it as reflecting the expectations and aspirations of the population;

- Awareness of the existence of pressures from the beneficiaries of the previous Status Quo, transient bearers of the adjustment and skeptical critics all imply the fragility of the domestic political support for the Structural Adjustment and Stabilization Programs;

- Recognize the importance and incorporate the "Social Dimensions of Adjustment" by developing safety nets to protect the under privileged, vulnerable population, and the unemployed from such short-term and medium-term economic dislocations of SAPs;

- Poverty levels and social indicators have to be considered in the introduction of Structural Adjustment and Stabilization policies;

- Need to recognize that a wide gap exists between organized developed market economies and developing African economies after decades of frustrated macro-economic management policies, low economic growth and development rates and fragile social conditions (World Bank, 2017);

- Measures to prevent temporary adverse effects of the SAPs for lesser income groups factored into the program costs to prevent such effects from degenerating to political opposition and unrest against the program and the government;

- Regarding the scope of the policy reform program, short-term advantages of "Big Moves" should be counter-balanced by the need to maintain policy consistency and sustainability in the long-term;

- Consideration has to be given to the political and economic strength and capacity of the social groups negatively affected by the policy initiatives and the possibilities open to the government to target measures to compensate or protect those losing from such policies; 
- Policy packages should concentrate on eliminating the most visible constraints, and the intensity of the policy measures should take into consideration the fact that policy games will probably continue for a long-term in the future;

- Negative long-term socio-economic consequences of SAPs could be avoided if indiscriminate reductions in public investment have been replaced by a more careful analysis of priorities regarding investment programs. Economic growth performance after Macro-Economic Policy Reform Programs could be improved by greater awareness of the complementarity between public and private investments;

- For multilateral agencies and institutions to define the appropriate timeframe policy-based loans for most fragile and less developed African economies, special funding with flexible periods and a carefully locally-based research capability. Support for locally-based research is essential to increase efficiency in the areas of domestic and international resources for the improvement of general economic and social conditions in Africa;

- Government ownership of the Programs is a prerequisite for success. It is therefore essential that the design of the Programs be based on a diagnosis of the most critical socio-economic distortions and imbalances afflicting the economy of the country and that there be concern regarding realistic targeting and timing for tranching and reducing the social costs of long-lasting Stabilization and Structural Adjustment programs;

- Political strategies for sustaining African economies should involve the building of coalitions of the beneficiaries of Structural Adjustment and Stabilization Programs. For example, the establishment of the economic organizations for the recipients of economic policy reforms like the exporter associations;

- It is vital to recognize that a technically well-designed program is a necessary but not a sufficient condition for socio-economic and political sustainability. For this reason, the African governments need to explain the program to the public in general and the potential losers and beneficiaries in particular (Chang, 2009);

- Stabilization and Structural Adjustment programs should be designed and presented with an awareness of the importance of the political sustainability of building a coalition of groups benefiting from and expanding as a result of the policy reform process. Protection of the poor, vulnerable and the less privileged also contributes to the sustainability of policy reform and is an objective in itself.

- Distribution of Conditionality. Efforts should be made to move closer to the causes of the slow rate of economic restructuring and policy responses in African countries. For example, within the industrial sector, emphasis should be shifted from investment incentives towards pricing policy, entry barriers, regulatory environment, technology, and innovation policy;

- Sequencing of Policy Reforms. The policy e.g., should address the manifestations of severe macroeconomic imbalances (like high inflation rates and unemployment) at the beginning of the Stabilization and Structural Adjustment Policy programs. The adjustment lending to support any other reforms is most likely to be operative after structural transformations aimed at reducing the extreme macroeconomic imbalances underway. For example, (a) Export Incentives should be improved (through devaluation, retention of foreign exchange and access to imported inputs) before the general liberalization of imports so that revenues from export commence to rise afore demand for imports begin; and (b) Financial Sector Reforms and credit availability should be considered early in the stabilization and adjustment programs;

- Comprehensive Approaches to Reforms. Need for a more understood approach to the design and implementation of SAPs covering a wide range of policy areas, particularly those areas which support a supply-side response (e.g., financial restructuring, regulatory policies, the business environment, institutional strengthening, and capacity building);

- World Bank-IMF Coordination. The design of IMF Stabilization Programmes in African countries address fundamental macro-economic imbalances but usually without an in-depth analysis of their root causes and inter-sectoral implications of macro-economic policy reforms. The greater success of programs might have been achieved if the IMF and World Bank work together to design and coordinate SAPs in the African countries; 
- Economic and Sector Works are essential to obtain the in-depth understanding required for the design of projects and to stimulate dialogue with country officials. Sectoral reviews, analysis of the structure of protection, and action-oriented study of the regulatory system are very crucial.

- Government Involvement and Commitment. The government officials have had minimal or no direct involvement in the design of SAPs and generally agree to conditions mainly because they need the financial aid, for example, the case of Côte d'Ivoire and Zambia. Since the roles of IMF and World Bank are viewed suspiciously in Africa, any success in achieving the effective implementation of SAPs depends chiefly on whether African governments retain the initiative as the originator of the program like in the case of Ghana;

- Implementation Capacity and Capability of Governments. Although the government commitment may be very stout in some African countries, the implementation capacity and capability at administrative and technical levels are inadequate and lacking in some countries. It is, therefore, primordial for the IMF and World Bank to undertake an in-depth analysis of the institutional, administrative and technical capacity of the concerned African countries before introducing the policy reform programs.

\section{Role of Multilateral Institutions in Enhancing Macro-Economic Policy-Reform Programs}

- Help African governments to analyze the deterioration of economic and social conditions of the poor, less privileged and the disadvantaged;

- Provide foreign exchange support for dollar-starved African economies while the fundamentals are taken care of;

- Facilitate debt relief and access to multilateral international capital and financial markets.

- Increase the credibility of local currencies through the provision of financial safety nets to sustain a realistic exchange rate parity;

- Increase overall economic flexibility through financing the cost of deregulation and other marketenhancing economic policies;

- Finance the expenditures of the reform programs associated with privatization and public sector reforms to increase policy effectiveness and recover investments in the social and economic infrastructures;

- Fund the implementation of sensible sectoral policies, capable of reducing the time between economic stabilization and the response of foreign and domestic private investment;

- Provide contingency support in the case of abrupt variations of interest rates or the prices of primary commodities when they are much more unfavorable than envisaged during the design of the policy reform programs in Africa.

There is no doubt that the various stabilisation and adjustment reforms and programmes initiated by the IMF and World Bank have, to some extent, contributed to improving the socio-economic development of African countries. However, most of them did not take into account the realities and nature of the African economies. Also, the poor and the vulnerable were not at the center of the programs implemented by the IMF and the World Bank in Africa. In other words, the social dimension of African economies (health, education, poverty, employment, etc.) were not considered in the enactment and implementation of the SAPs, as well as the recent economic, and financial reforms put in place in CEMAC.

The stabilization and structural programs put in place in CEMAC and Africa as a whole to a large extent neglected the wellbeing of man who is supposed to be at the center of all socio-economic development programs and policies. It was in this regard that the reforms and policy reforms put in place by the African countries with the help of the Bretton Woods institutions were considered not to have a human face.

To this extent, the policy reforms and programmes they implemented did more damage to the already fragile economies of the CEMAC and Africa. For instance, today, Africa habors about half of the world's needy, life expectancy and employment rate are the lowest on the continent compared to other regions of the globe (African Development Bank, 2018). All this is, to some degree, because the Macro-Economic Policy Programmes and the various recent economic and financial reforms implemented in the African countries did not take into account social aspects of development like employment, health and education which play a vital role in enhancing individual productivity and the total economic output and economic competitiveness of enterprises and economies. 


\section{Conclusion and Recommendations}

Since the 1960s, African economies have been vulnerable to external economic and financial crises which resulted from the fall in oil and commodity prices (African Development Bank, 2018). The perennial occurrence of the former in Africa have had widespread and profound negative impacts on the continent, which are reflected in an increase in unemployment and poverty levels.

However, the restructuring of African economies during the crisis has always been computing with the subsidiaries of Bretton Woods institutions (IMF, World Bank) that, to some point, impose measures and policies on African governments that are inappropriate to their economies. Thus, revealing the weakness of African governments to independently elaborate, implement, and follow-up programs and policies that can improve their socio-economic and development situation. To this extent, African countries should always utilize local experts in the elaboration, implementation, and follow-up of their socio-economic development programs and policies to significantly reduce their dependence on foreign experts and international institutions.

Also, African countries should emphasize on the socio-economic situation of their economies and also anticipate the results of the policies and programs they intend to implement before their initiation. Redressing and adjusting African economies with the help of the IMF, World Bank, etc. would enable the continent to progress in its socioeconomic development. However, it is far from being enough or adequate to propel the continent to higher and sustainable economic growth rates that would harness and enhance the needed socio-economic development that would significantly reduce poverty and improve the living standards of the poor and vulnerable people.

To this effect, African countries can achieve long-term socio-economic development through industrialization enhanced by research, innovation, and technological development (United Nations Economic Commission for Africa, 2011). Therefore, adjustment and stabilization policies or reforms or programs should be accompanied with an improved business environment that would enable enterprises on the continent to thrive and also make it less vulnerable to external shocks resulting from the fluctuation of oil and commodity prices on which it heavily depends for revenue. Thus, sound industrial policies should be elaborated and implemented to enable large-scale production of higher value-added products, the creation of more decent and well-remunerated jobs, increase export earnings, reduce poverty and improve the living standards of the majority of the people on the continent (African Development Outlook, 2018).

\section{References}

African development Bank (2019). Central Africa Economic Outlook 2019. Macro-Economic Performance and Prospects, and Regional Integration in Central Africa. Abidjan.

African Development Bank (2018). African Economic Outlook, 2018 Edition. Abidjan.Cameroon Chamber of Commerce, Industry, Mines and Craft (2018). Report on the Economic Situation of Cameroon in 2017. Yaounde.

Chang, H, J. (2009). Economic History of the Developed World: Lessons for Africa. A Lecture Delivered in the Eminent Speakers programme of Africa Development Bank, University of Cambridge.

Commission de la CEMAC (2018). Vers une Intégration Accélérée pour une CEMAC Emergente : Renouveau Communautaire 2012-2018.

Economic Commission for Africa (2011). Industrial Policies for the Structural Transformation of African Economies: Options and Best Practices. ECA Research Paper on Policies, No. 2. Addis Ababa.

International Labour Organization (1997). Jobs for Africa: A Policy Framework for Employment Intensive Growth Strategy, (Geneva, 1997). pp. 33-37.

Paul, C., and Jan, G. (1999). Explaining African Economic Performance. Journal of Economic Literature, Vol. 37, March, 1999, pp.61-111.

Robert, B., and Jong, W, L, C. (1993). Losers and Winners in Economic Growth in Proceedings of the World Bank Annual Conference on Development Economics. pp. 267-97.

World Bank (2017). End Extreme Poverty, Boost Shared Prosperity. Annual Report 2017. 